\title{
Multi-Objective Approach for Determining Optimal Sustainable Urban Drainage Systems Combination at City Scale. The Case of San Luis Potosí (México)
}

\author{
Sergio Zubelzu ${ }^{1, *}$, Leonor Rodríguez-Sinobas ${ }^{1}$, Alvaro Sordo-Ward ${ }^{2}{ }^{\mathbb{D}}$, Alan Pérez-Durán ${ }^{3}$ and \\ Rodolfo Cisneros-Almazán ${ }^{3}$ \\ 1 Escuela Técnica Superior de Ingeniería Agronómica, Alimentaria y de Biosistemas, Universidad Politécnica \\ de Madrid, Av. Puerta de Hierro, 2, 28040 Madrid, Spain; leonor.rodriguez.sinobas@upm.es \\ 2 Escuela Técnica Superior de Ingenieros de Caminos, Canales y Puertos, Universidad Politécnica de Madrid, \\ Calle del Prof. Aranguren, 3, 28040 Madrid, Spain; alvaro.sordo.ward@upm.es \\ 3 Facultad de Ingeniería, Universidad Autónoma San Luis de Potosí Dr. Manuel Nava No. 8, Col. Zona \\ Universitaria Poniente, San Luis Potosí C.P. 78290, S. L. P., Mexico; A302262@alumnos.uaslp.mx (A.P.-D.); \\ cisnerro@uaslp.mx (R.C.-A.) \\ * Correspondence: sergio.zubelzu@upm.es; Tel.: +31-910670993
}

Received: 11 February 2020; Accepted: 13 March 2020; Published: 16 March 2020

\begin{abstract}
A method for determining the optimal Sustainable Urban Drainage Systems (SUDs) combination at city scale is presented in this paper. A comprehensive set of SUDs categories comprising infrastructures aimed at either detaining and locally reusing or infiltrating precipitation are considered. A volumetric water balance is proposed for modelling hydrological processes in urban catchments. A multi-criteria approach combining a cost function and aims for both recharging aquifers and limiting runoff contribution to water courses is proposed to find the optimal SUDs combination. The water balance was run with each possible SUDs combination and the optimal set of SUDs was found. The method was applied to the Metropolitan Area of San Luis Potosí (Mexico). The optimal solutions in this case clearly promoted surface runoff detention and reuse over porous pavements and green roofs but they were sensitive to the considered costs. The SUD requirements to potential new urban developments for each catchment to comply with the original hydrological aims were also studied. The method requires customizing the cost function and using representative climatic data.
\end{abstract}

Keywords: stormwater management; surface runoff; water reuse; low impact development; sustainable urban drainage systems; volumetric water balance; urban catchment

\section{Introduction}

Sustainable Urban Drainage Systems (SUDs) have gained relevancy as efficient solutions for optimal water management in urban areas. While traditional management seeks to rapidly harvest runoff to be treated and discharged to watercourses, SUDs represent a new paradigm that seeks to handle runoff locally. SUDs encompass different types of facilities such as green roofs, permeable pavements, infiltration trenches, detention areas, rain gardens, etc.

Several initiatives have recently been developed to install SUDs in urban areas [1-4]. Scientific literature has widely focused on this topic [5-7], some studies have addressed the optimal SUD combination at the urban planning stage [8-12], while others have studied possible locations or have proposed multi-objective functions for determining the optimal SUDs location [13-16].

Despite the number of studies addressing SUDs, some unsolved questions remain. First, a detailed definition of the SUD design aim has not been thoroughly discussed by the literature that, in most 
cases, does not go beyond simple goals such as minimizing runoff, maximizing aquifer recharge, or minimizing cost functions. From a theoretical point of view, this target has to be considered in close relation to the set of variables involved in the whole hydrological system since SUDs alter several processes involved. For example, runoff detainment reduces surface discharge to watercourses which, although desired above certain levels, undoubtedly limits streamflow which can affect ecological flows. Otherwise, infiltration of stored runoff into vegetated soils through for example infiltration trenches without further consideration of evapotranspiration could lead to water losses by deep percolation.

Similarly, SUDs design criteria have traditionally relied on the same design standards of traditional draining infrastructures. Standards of SUDs design usually seek to mimic the hydrology of the pre-development state [17] setting up limits of peak flow and runoff volume for different storm events. In line with such guidelines, studies aimed at either defining general planning strategies or particular SUDs design, often use specific extreme events for analyzing SUDs behavior. Several authors have discussed the validity of using extreme storm events for SUDs design based on the fact that such facilities are not aimed at collecting runoff with security purposes but for managing runoff [18].

Otherwise, studies aimed at finding the optimal SUDs combination at the planning stage usually chose among a set of enclosed alternatives encompassing a reduced type of SUDs whose set-up was previously defined, (see, for example, [19]). Studies tackling SUDs design comprising all possible combinations, even the absence, of SUDs to deduce the optimal solution are still lacking.

The present paper proposes a method for determining the optimal SUDs combination at a city scale encompassing the complete hydrological system. A comprehensive set of SUDs categories comprising infrastructures aimed at either detaining and locally reusing runoff or infiltrating precipitation is considered. For that purpose, hydrological dynamics are modeled with a water balance. A multi-criteria decision process encompassing both economic and hydrological aims completes the framework.

\section{Materials and Methods}

The state equation for a linear hydrological system (Equation (1)) relates inputs $(I P)$, outputs $(O)$ and internal system variation $(S)$ as time functions:

$$
\frac{d S}{d t}=I P(t)-O(t)
$$

For the proposed urban hydrological cycle, the soil water content $(\theta)$ varies as a result of evapotranspiration $(E T k)$, precipitation $(P)$, aquifers recharge $(D)$ and runoff $(R)$.

$$
\frac{d \theta}{d t}=P(t)+I(t)-E T k(t)-D(t)-R(t)
$$

Three types of SUD categories comprising most of the SUD facilities were considered:

1. SUDs aimed at detaining and storing runoff for local reuse

The set of SUDs aimed at detaining and storing runoff are defined in the present model as $k_{i}$ rates of runoff detained at each $i$ land use, while the remaining portion of $R$ goes to conventional urban draining infrastructure (CUD).

$$
R(t)=\sum k_{i} R_{i}(t)+C U D(t)
$$

The summation in (3) represents the volume of water stored (VSUD) for local reuse. The maximum value for the summation in Equation (3) represents the maximum volume of water to be stored which in turn represents the SUDs design parameter $\left(V S U D_{M A X}\right)$. Storing tanks or ponds for local reuse, infiltration trenches or wells, infiltration cells, rain gardens, etc. can be included within this SUDs category. 
2. SUDs aimed at easing the direct infiltration of precipitation

Porous pavements, or equivalent facilities, are included in the model by the particular definition of the infiltration properties of each land use. For that purpose, $k p p_{i}$ rates representing the portion of the total area occupied by porous pavements were defined for each $i$ land use, and specific infiltration properties were assigned to these areas.

\section{Green roofs}

Green roofs were incorporated as green areas where runoff directly goes to CUD, infiltrated water stores within the soil up to saturation level, infiltrated water after the saturation is reached discharges to CUD, plants consume the soil water at ETk rate and the potential water deficit is covered with $I$. Similarly, $\mathrm{kgr}_{i}$ rates define the proportions of each land use occupied by green roofs.

Upon this general structure, the water balance (Equation (2)) simulations were run with the following assumptions.

- After an initial soil water content $\left(\theta_{0}\right)$ was defined, the subsequent estimation of $\theta$ allowed determining the daily irrigation requirements by comparison between the estimated $\theta$ and the triggering irrigation threshold $(\theta \mathrm{r})$. If $\theta<\theta \mathrm{r}$, then $V S U D$, if any, was used to increase $\theta$ to $\theta_{\mathrm{FC}}$. In the event of VSUD to be insufficient to increase $\theta$ to $\theta_{\mathrm{FC}}$, external irrigation (I) was provided.

- Daily potential evapotranspiration and precipitation were used to run the model daily. For a data series of several years, the daily average value of a sort of median interval (values within the interval mean $\pm 1.5 \times$ standard deviation) was used. Therefore, a representative climatic year was selected to run the water balance.

- The incoming water to VSUD exceeding its storage capacity $\left(V S U D_{M A X}\right)$ discharged to CUD.

- The aquifer was recharged $(D)$ by the water infiltrated into the vegetated soil after $\theta$ equals saturation $(\theta s)$ and by the infiltrated water, if any, in paved areas. In green roofs, runoff and excess of infiltrated water when $\theta$ exceeds saturation level also discharged to CUD.

- To avoid problems arising with regard to the duration of storm events, and to simplify the incorporation of porous pavements and green roofs to the water balance, the Soil Conservation System curve number method was used to estimate runoff volumes. Each daily precipitation value was supposed to define a unique storm event.

The water balance was computed, for each possible combination of SUDs implemented by $k_{i}, \mathrm{kgr}_{i}$ and $k p p_{i}$, daily, with daily $P$ and ETk (a crop coefficient $k c c=1$ was considered to transform ET0 into ETk) data and supposing $\theta_{0}$ to be 0.2. The annual aggregated $D, I$ and $C U D$ were estimated and the following cost function was computed for each SUDs combination. The sets of SUDs minimizing CT (Aggregated cost) and complying with the constraints were selected.

$$
\begin{gathered}
C T=\text { VSUD }_{M A X} \times \operatorname{CUVSUD}+\Sigma C U S U D_{i} \times k_{i} \times R_{i}+\text { CUCUD } \times C U D+C U I \times I \\
+C U p p \times \Sigma k p p_{i} \times S_{i}+C U g r \times \Sigma k g r_{i} \times S_{i} \\
\text { st }: \\
D \geq D \text { min } \\
\text { CUDmin } \leq \text { CUD } \leq \text { CUDmax }
\end{gathered}
$$

where:

- VSUD $D_{M A X}$ represents the runoff storing capacity.

- $\quad$ CUVSUD is the unitary cost $\left(€ / \mathrm{m}^{3}\right)$ of the storing elements.

- $\quad C U S U D_{i}$ is the unitary cost $\left(€ / \mathrm{m}^{3}\right)$ of detaining, storing and reusing runoff at each land use.

- CUCUD represents the unitary cost $\left(€ / \mathrm{m}^{3}\right)$ of managing runoff through conventional draining facilities. 
- $\quad C U I$ is the unitary cost of irrigating $\left(€ / \mathrm{m}^{3}\right)$.

- $\quad$ CUpp is the unitary cost of porous pavements $\left(€ / \mathrm{m}^{2}\right)$.

- $\quad C U g r$ represents the unitary cost of green roofs $\left(€ / \mathrm{m}^{2}\right)$.

- $\quad \Sigma k p p_{i} \times S_{i}$ and $\Sigma k g r_{i} \times S_{i}$ represent the areas occupied by either porous pavements or green roofs. Two hydrological objectives were added to economic criteria:

- $\quad D \geq D$ min: the aquifer to be recharged above a given limit seeking to either comply with environmental objectives or to replenish water withdrawals.

- $\quad C U D$ min $\leq C U D \leq C U D$ max: supposed that CUD finally goes to watercourses, this constraint seeks to maintain ecological flows but not exceeding an upper limit to prevent flooding risks. The unknowns of the optimization problem were $V S U D_{M A X}$ and $k p p_{i}, k g r_{i}$, and $k_{i}$ rates.

Case Study

The Metropolitan Area of San Luis Potosí is located approximately 400 km north-west of México City at the south-east end of the Sierra Madre Occidental with an area of $2409.2 \mathrm{~km}^{2}$ (see Figure 1).

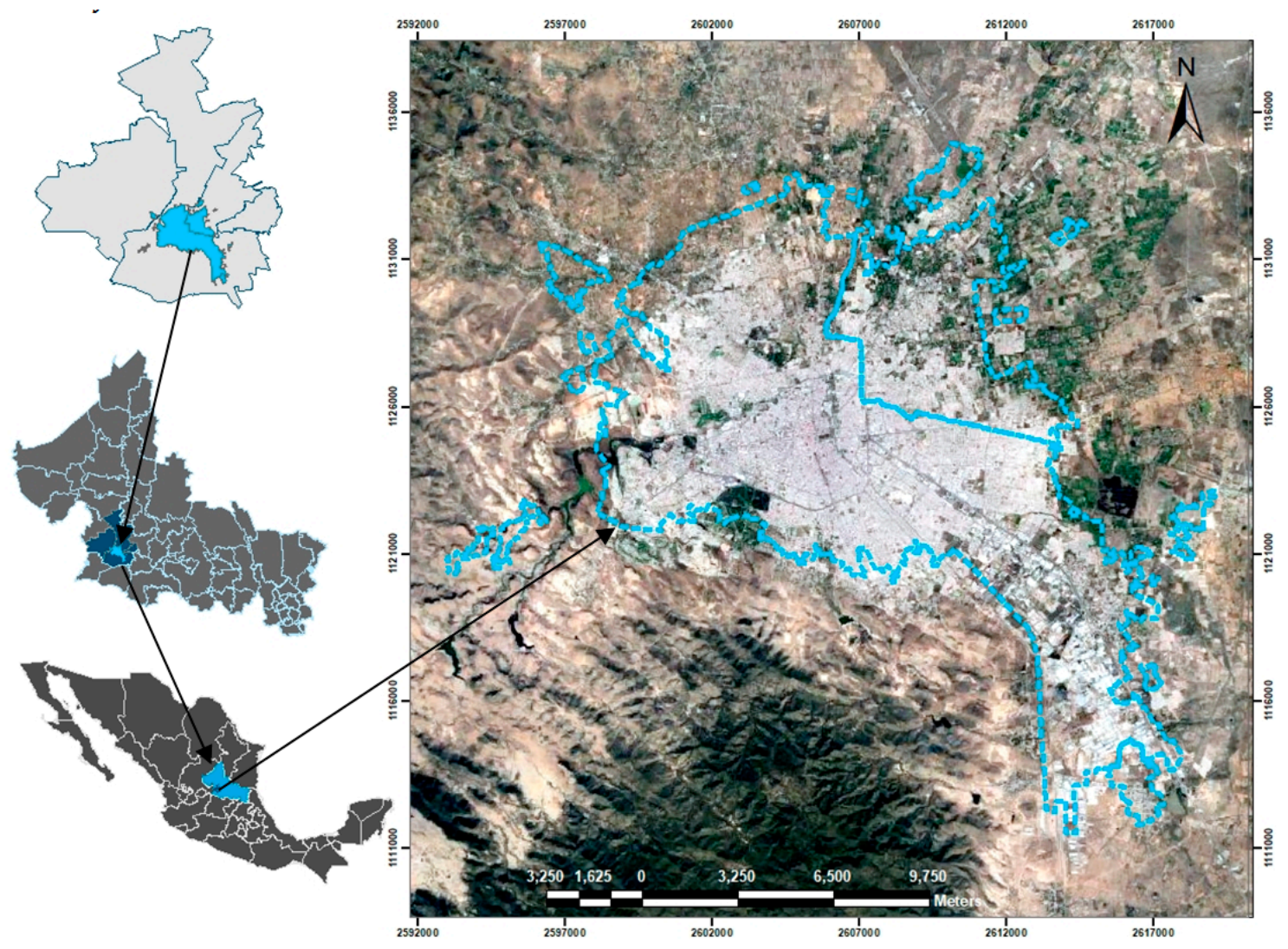

Figure 1. Location of San Luis Potosí.

The region has a semiarid climate with mean temperature, precipitation, and potential evapotranspiration around $17{ }^{\circ} \mathrm{C}, 400 \mathrm{~mm}$, and $2033 \mathrm{~mm}$, respectively [20]. The valley of San Luis Potosí, located at the hydrological region 37 "El Salado," has no natural perennial surface drainage. The total availability of surface water stored in dams to supply the Metropolitan Area of San Luis Potosí is $10.176 \mathrm{Mm}^{3}$ [21]. Yearly average groundwater extraction amounts to approximately $125.6 \mathrm{Mm}^{3}$ per year distributed as follows (see Table 1). 
Table 1. Groundwater extraction ( $\mathrm{Mm}^{3} /$ year).

\begin{tabular}{cccc}
\hline Uses & Upper Aquifer & Deep Aquifer & Total \\
\hline Potable urban water & 0.167 & 84.389 & 84.419 \\
Agriculture & 3.64 & 20.449 & 24.084 \\
Industrial & 0.096 & 9.650 & 9.746 \\
Agroindustry & 0.157 & 0.027 & 0.184 \\
Urban services & 0.452 & 5.198 & 5.650 \\
Livestock & 0.25 & 0.661 & 0.911 \\
Other & 0.18 & 3 & 0.006 \\
Total & 4.969 & 120.609 & 125.578 \\
\hline
\end{tabular}

The installed capacity of wastewater treatment plants is $1889.4 \mathrm{~L} / \mathrm{s}$ (Table 2) and the treated flow $1575.89 \mathrm{~L} / \mathrm{s}$ [22].

Table 2. The capacity of facilities for wastewater treatment.

\begin{tabular}{ccc}
\hline Treatment Plant & Installed Capacity (L/s) & Treated Flow (L/s) \\
\hline Tangamanga IB & 110 & 110 \\
North - Tangamanga II & 400 & 240 \\
Club de Golf & 40 & 40 \\
Agua tratada del potosí & 50 & 30 \\
Tangamanga IA & 40 & 40 \\
Potosino Sports Club & 1.4 & 1.4 \\
Tanque Tenorio & 1050 & 1000 \\
Deportivo Lomas & 100 & 40 \\
Villa Antigua & 11 & 6 \\
Valle de los Cedros & 10 & 6 \\
Villa Magna & 16 & 2 \\
Fracc El Pedregal & 20 & 20 \\
IMMSA & 40 & 40 \\
Loma Prieta & 0.76 & 0.25 \\
El Refugio & 0.24 & 0.24 \\
Total & 1889.4 & 1575.89 \\
\hline
\end{tabular}

Three catchments were delineated in the metropolitan area of San Luis Potosí for analyzing SUDs alternatives. Figure 2 depicts the identified catchments and Table 3 presents the land use areas within each catchment.

Table 3. Land use areas $\left(10^{4} \mathrm{~m}^{2}\right)$ by catchment.

\begin{tabular}{cccccc}
\hline Catchment & $\begin{array}{c}\text { Urban } \\
\text { Intensive (in) }\end{array}$ & $\begin{array}{c}\text { Urban } \\
\text { Semi-Intensive (sin) }\end{array}$ & $\begin{array}{c}\text { Green Zones/Sport } \\
\text { Facilities (zzvv) }\end{array}$ & Rural (ag) & Total \\
\hline $\begin{array}{c}\text { Subsector } 1 \\
\text { (SZ1) }\end{array}$ & 1406.67 & 1347.23 & 690.35 & 9557.09 & $13,001.35$ \\
$\begin{array}{c}\text { Subsector } 2 \\
\text { (SZ2) }\end{array}$ & 1231.87 & 3015.90 & 1465.49 & $11,334.31$ & $17,047.58$ \\
$\begin{array}{c}\text { Subsector 3 } \\
\text { (SZ3) }\end{array}$ & 856.29 & 1305.14 & 1089.60 & 3929.98 & 7181.00 \\
\hline
\end{tabular}




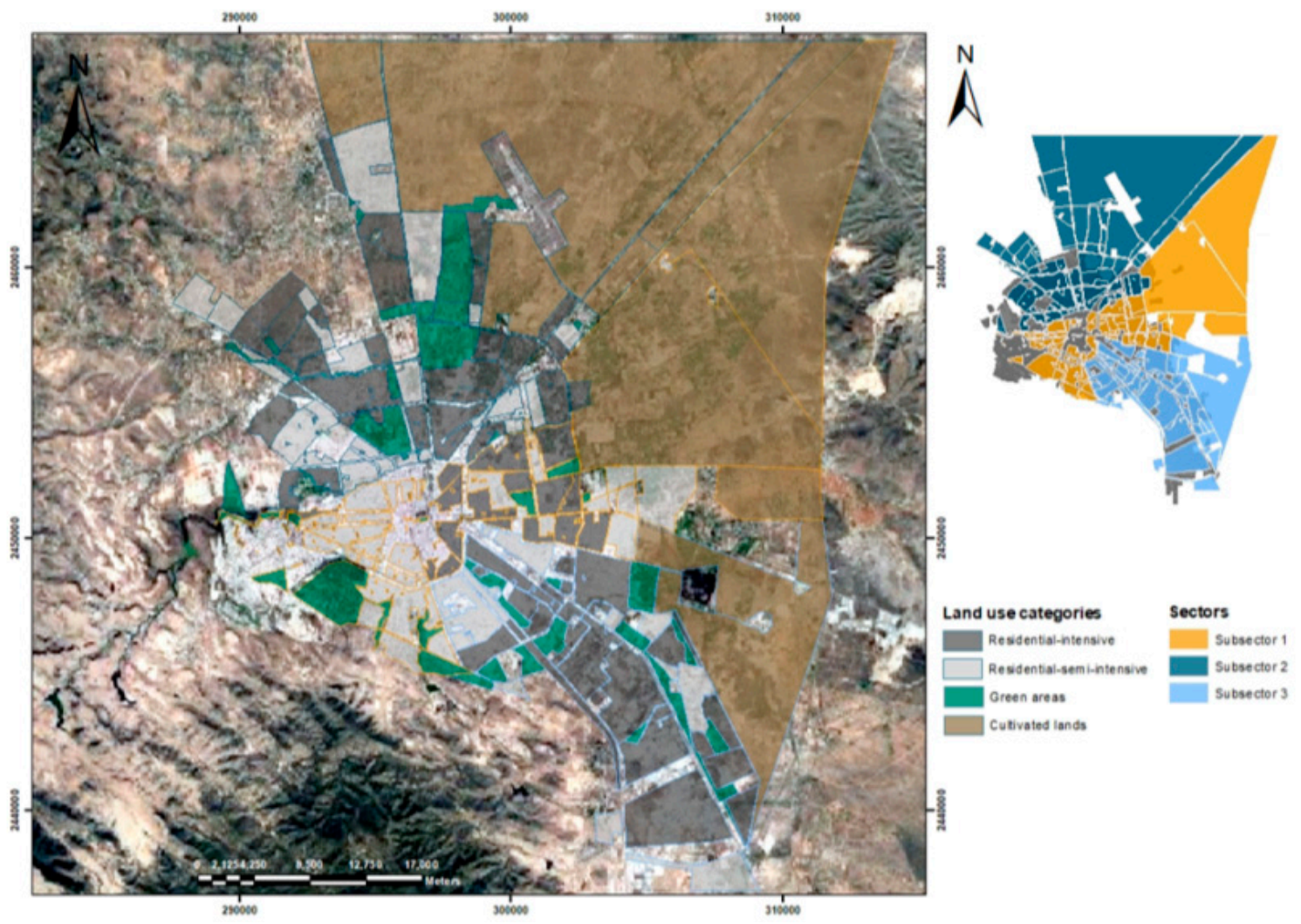

Figure 2. Catchments delineated in the metropolitan area of San Luis Potosí (numbers of axis represent UTM coordinates).

\section{Results}

Table 4 presents the costs used in the optimization model.

Table 4. Unitary costs for the optimization problem.

\begin{tabular}{cc}
\hline Cost & Value \\
\hline CUCUD $\left(€ / \mathrm{m}^{3}\right)$ & 1.99 \\
CUI $\left(€ / \mathrm{m}^{3}\right)$ & 1.68 \\
CUVSUD $\left(€ / \mathrm{m}^{3}\right)$ & 0.315 \\
CUSUD $_{\text {in }}\left(€ / \mathrm{m}^{3}\right)$ & 0.1 \\
CUSUD $_{\text {sin }}\left(€ / \mathrm{m}^{3}\right)$ & 0.1 \\
CUSUD $_{z z v v}\left(€ / \mathrm{m}^{3}\right)$ & 0.8 \\
CUSUD $_{a g}\left(€ / \mathrm{m}^{3}\right)$ & 0.9 \\
CUpp $\left(€ / \mathrm{m}^{2}\right)$ & 25 \\
CUgr $\left(€ / \mathrm{m}^{2}\right)$ & 25 \\
\hline
\end{tabular}

CUCUD, CUI, and CUVSUD were retrieved from [18]; CUSUDin, CUSUDsin, CUSUDzzvo, CUSUDag, CUpp, and CUgr were defined with the aid of local agents. These costs, in particular the ones for porous pavements and green roofs, agree with the SUDs costs in other studies, for example in [18]. The costs were updated at a hypothetical starting project date and include both building and operation costs. Table 5 presents the Curve Number values (CNs) used for runoff estimation.

Table 5. Curve Numbers (CNs) of each land use, porous pavement and green roofs.

\begin{tabular}{cccccc}
\hline$C N_{\text {in }}$ & $C N_{\text {sin }}$ & $C N_{z z v v}$ & $C N_{a g}$ & $C N_{p p}$ & $C N_{g r}$ \\
\hline 98 & 92 & 90 & 85 & 85 & 85 \\
\hline
\end{tabular}


Tables 6 and 7 present the estimates obtained with Equation (2) for, respectively, the current land use distribution presented in Table 3 and the hypothetical original situation where the entire land would be completely occupied by rural areas.

Table 6. Main water balance variables for the current state.

\begin{tabular}{ccccc}
\hline Catchment & $\boldsymbol{D}\left(\mathbf{m}^{\mathbf{3}} /\right.$ year $)$ & $\boldsymbol{C U D}\left(\mathbf{m}^{3} /\right.$ year $)$ & $\boldsymbol{I}\left(\mathbf{m}^{3} /\right.$ year $)$ & $\boldsymbol{C} \boldsymbol{T}(\boldsymbol{€} /$ year $)$ \\
\hline SZ1 & $50,497,634.69$ & $3,741,781.23$ & $1,965,519.25$ & $11,409,716.99$ \\
SZ2 & $64,526,169.28$ & $4,607,891.62$ & $4,172,428.50$ & $16,840,884.21$ \\
SZ3 & $25,238,222.93$ & $2,209,662.10$ & $3,102,213.31$ & $10,270,445.96$ \\
\hline
\end{tabular}

Table 7. Main water balance variables for the pre-development state.

\begin{tabular}{ccc}
\hline Catchment & $\boldsymbol{D}\left(\mathbf{m}^{3} /\right.$ year $)$ & Surface Runoff to Watercourses $\left(\mathbf{m}^{3} /\right.$ year $)$ \\
\hline SZ1 & $54,328,896.67$ & $2,356,980.36$ \\
SZ2 & $71,236,927.95$ & $3,090,510.77$ \\
SZ3 & $30,007,351.85$ & $1,301,825.42$ \\
\hline
\end{tabular}

For finding the optimal combination of SUDs the cost function was defined as follows.

$$
\begin{aligned}
& \text { Min CT }=C U D \times C U C U D+I \times C U I+V S U D_{M A X} \times C U S U D+k i n \times R i n \times C U S U D i n+ \\
& k \sin \times R \sin \times \text { CUSUDsin }+k z z v v \times R z z v v \times \text { CUSUDzzvv }+k a g \times R a g \times \text { CUSUDag+ } \\
& (k p p i n \times \operatorname{Sin}+k p p \sin \times \operatorname{Ssin}+k p p z z v v \times S z z v v) \times C U p p+(k g r i n \times \operatorname{Sin}+k g r \sin \times \operatorname{Ssin}) \times C U g r \\
& \text { st : } \\
& 0 \leq k i n, k s i n, k z z v v, k a g \leq 1 \\
& 0 \leq \text { kppin, kppsin, kgrin, kppzzvv, kgrsin } \leq 0.3 \\
& 100,000 \leq \operatorname{VSUD}_{M A X} \leq 4,600,000,
\end{aligned}
$$

Potential areas suitable for porous pavements and green roofs do not reach the total area of each land use $\left(k p p_{i}, k g r_{i} \leq 0.3\right)$ as such facilities can only be installed at certain zones (green roofs at buildings and porous pavements out of buildings and unpaved areas). In addition, it was assumed that only at in and sin land uses green roofs can be installed while only in, sin and zzvv lands are suitable for porous pavements. On the contrary, kin, ksin, kzzvv, and kag were let to vary between zero and one as it was assumed that the runoff detention rate can perfectly vary between zero and one. VSUD MAX was limited to the maximum runoff appearing if the maximum precipitation (historical data series) falls.

Replenishing water withdrawals was considered for limiting $D$. For each catchment, $D$ was imposed to be larger than the proportional rate (according to the area of each catchment over the total area of San Luis Potosí) of the annual aquifer extractions estimated to be $1.25 \times 10^{6} \mathrm{~m}^{3} /$ year (see Table 1).

The amount of runoff conveyed to CUD to feed watercourses was imposed to be smaller than the pre-development values (Table 6) and larger than the supposedly original ones (Table 7) to ensure that SUD implementation keeps potential ecological flow rates without increasing the actual flooding risk.

Table 8 summarizes the limits for $D$ and CUD.

Table 8. Summary of bounds for D and CUD $\left(\mathrm{m}^{3}\right)$.

\begin{tabular}{cccc}
\hline Variable & SZ1 & SZ2 & SZ3 \\
\hline$D$ & $\geq 42,704,000$ & $\geq 56,520,000$ & $\geq 23,864,000$ \\
CUD & $\geq 2,356,980.36$, & $\geq 3,090,510.77$, & $\geq 1,301,825.42$, \\
& $\leq 3,741,781.23$ & $\leq 4,607,891.62$ & $\leq 2,209,662.10$ \\
\hline
\end{tabular}

The multi-objective problem was solved to find the combination of kin, ksin, kzzvv, kag, kppin, kppsin, kppzzvo, kgrin, kgrsin, and VSUD ${ }_{M A X}$ complying with the proposed restrictions and minimizing 
the cost function. All possible combinations of these variables were checked computing the water balance and $C T$, and the optimal values were obtained (Table 9).

Table 9. Optimal combination of SUDs by catchment.

\begin{tabular}{cccc}
\hline SUD & SZ1 & SZ2 & SZ3 \\
\hline$k_{\text {ppin }}$ & 0.0 & 0.0 & 0.0 \\
$k_{\text {ppsin }}$ & 0.0 & 0.0 & 0.0 \\
$k_{\text {ppzzvv }}$ & 0.0 & 0.0 & 0.0 \\
$k_{\text {grin }}$ & 0.0 & 0.0 & 0.0 \\
$k_{\text {grsin }}$ & 0.0 & 0.0 & 0.0 \\
$V S U D_{M A X}\left(m^{3}\right)$ & $1,100,000$ & $1,100,000$ & $1,100,000$ \\
$k_{\text {zzvv }}$ & 0.1 & 0.0 & 0.2 \\
$k_{\text {ag }}$ & 0.0 & 0.0 & 0.0 \\
$k_{\text {in }}$ & 0.9 & 1 & 0.9 \\
$k_{\text {sin }}$ & 0.2 & 0.4 & 0.2 \\
$C T(€)$ & $6,616,706$ & $11,805,947$ & $7,055,552$ \\
\hline
\end{tabular}

From Table 9, it can be observed that green roofs and porous pavements are penalized by their larger cost in comparison with the costs of the facilities aimed at collecting and reusing runoff. Table 10 present the main variables of the water balance for the optimal SUDs combinations.

Table 10. Main variables of water balance for the optimal combination of SUDs.

\begin{tabular}{cccc}
\hline Catchment & $\boldsymbol{D}\left(\mathbf{m}^{3} /\right.$ year $)$ & CUD $\left(\mathbf{m}^{\mathbf{3}} /\right.$ year $)$ & $\boldsymbol{I}\left(\mathbf{m}^{\mathbf{3}} /\right.$ year $)$ \\
\hline SZ1 & $50,497,634.69$ & $2,357,176.78$ & $853,518.62$ \\
SZ2 & $64,526,169.28$ & $3,115,913.90$ & $3,030,168.29$ \\
SZ3 & $25,238,222.93$ & $1,305,844.86$ & $2,379,628.70$ \\
\hline
\end{tabular}

As it could be expected, the optimal SUDs combinations managed to reduce CUD to practically reach the pre-development state while $D$ largely exceeds the established minimum thresholds. $D$ and CUD mostly come from rural areas while runoff stored in VSUD is almost entirely detained in intensive and semi-intensive land use (Figure 3).

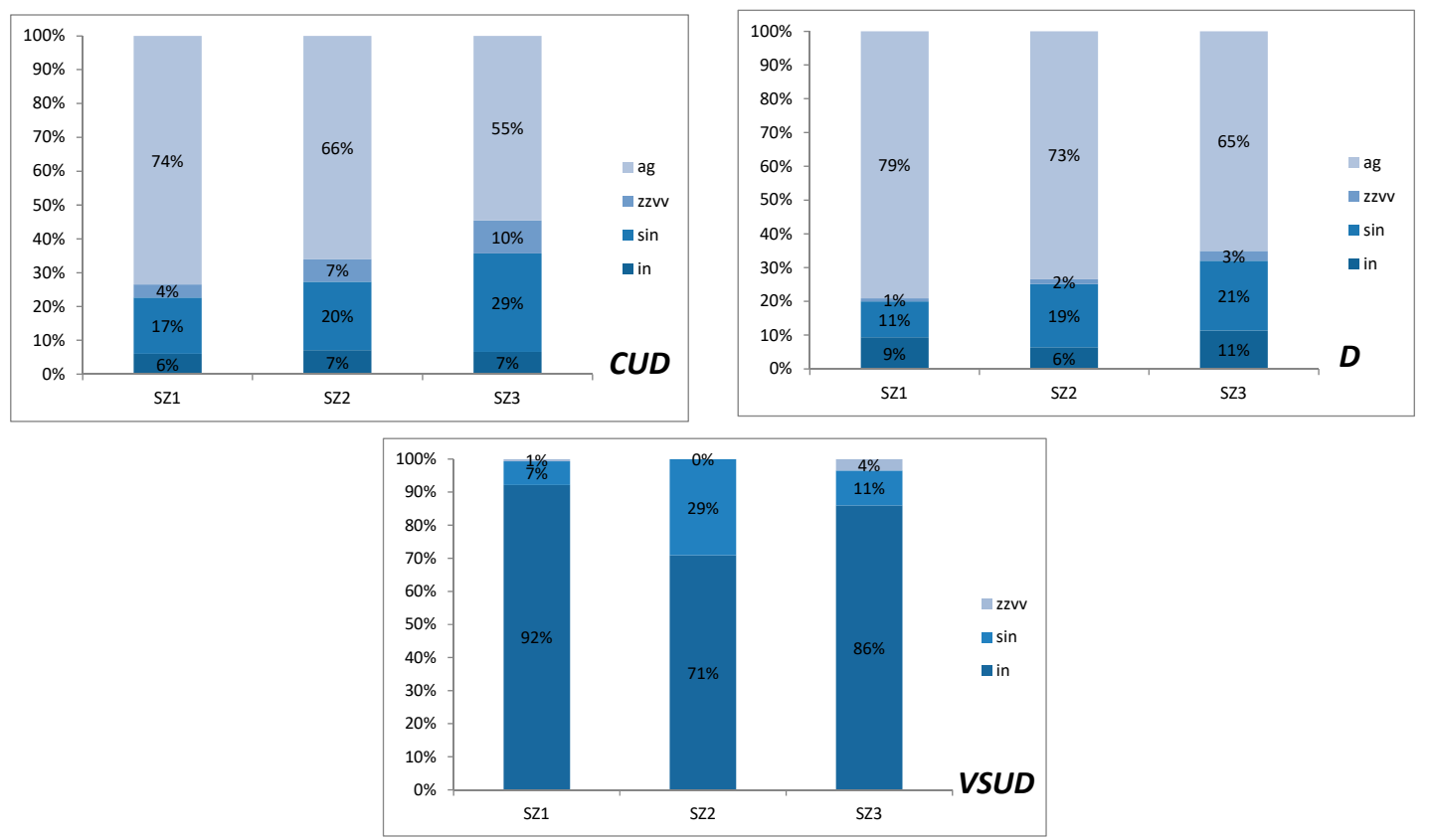

Figure 3. Land uses' contribution to $C U D, D$, and the volume of water stored (VSUD). 
Different scenarios were studied for each catchment (Table 11) either developing residential intensive areas at the expense of rural lands (keeping constant semi-intensive and green zones) or developing semi-intensive areas on rural lands (keeping constant intensive and green zones). The considered scenarios are presented in Table 11.

Figure 4 shows $D$ and $C U D$ calculated for each scenario together with their proposed thresholds (Dmin, CUDmin, CUDmax).

Table 11. Scenarios for analyzing the sensitivity of optimal SUDs combinations. Areas of land use by catchments $\left(10^{6} \mathrm{~m}^{2}\right)$.

\begin{tabular}{cccccccccccc}
\hline \multicolumn{2}{l}{ Catchment/Land Use } & $\mathbf{1}$ & $\mathbf{2}$ & $\mathbf{3}$ & $\mathbf{4}$ & $\mathbf{5}$ & $\mathbf{6}$ & $\mathbf{7}$ & $\mathbf{8}$ & $\mathbf{9}$ & $\mathbf{1 0}$ \\
\hline \multirow{2}{*}{ SZ1 } & Intensive & 14.07 & 23.62 & 40.83 & 61.47 & 80.74 & 95.19 & 103.86 & 107.90 & 109.29 & 109.60 \\
& Rural & 95.57 & 86.01 & 68.81 & 48.17 & 28.90 & 14.45 & 5.78 & 1.73 & 0.35 & 0.03 \\
\multirow{2}{*}{ SZ2 } & Intensive & 12.32 & 23.65 & 44.05 & 68.54 & 91.39 & 108.52 & 118.81 & 123.61 & 125.25 & 125.62 \\
& Rural & 113.34 & 102.01 & 81.61 & 57.12 & 34.27 & 17.14 & 6.85 & 2.06 & 0.41 & 0.04 \\
\multirow{2}{*}{ SZ3 } & Intensive & 8.56 & 12.49 & 19.57 & 28.06 & 35.98 & 41.92 & 45.49 & 47.15 & 47.72 & 47.85 \\
& Rural & 39.30 & 35.37 & 28.30 & 19.81 & 11.88 & 5.94 & 2.38 & 0.71 & 0.14 & 0.01 \\
SZ1 & Semi-intensive & 13.47 & 23.03 & 40.23 & 60.88 & 80.14 & 94.59 & 103.26 & 107.31 & 108.70 & 109.01 \\
& Rural & 95.57 & 86.01 & 68.81 & 48.17 & 28.90 & 14.45 & 5.78 & 1.73 & 0.35 & 0.03 \\
SZ2 & Semi-intensive & 30.16 & 41.49 & 61.90 & 86.38 & 109.23 & 126.36 & 136.65 & 141.45 & 143.09 & 143.46 \\
& Rural & 113.34 & 102.01 & 81.61 & 57.12 & 34.27 & 17.14 & 6.85 & 2.06 & 0.41 & 0.04 \\
SZ3 & Semi-intensive & 13.05 & 16.98 & 24.06 & 32.54 & 40.47 & 46.41 & 49.97 & 51.64 & 52.21 & 52.34 \\
& Rural & 39.30 & 35.37 & 28.30 & 19.81 & 11.88 & 5.94 & 2.38 & 0.71 & 0.14 & 0.01 \\
\hline
\end{tabular}
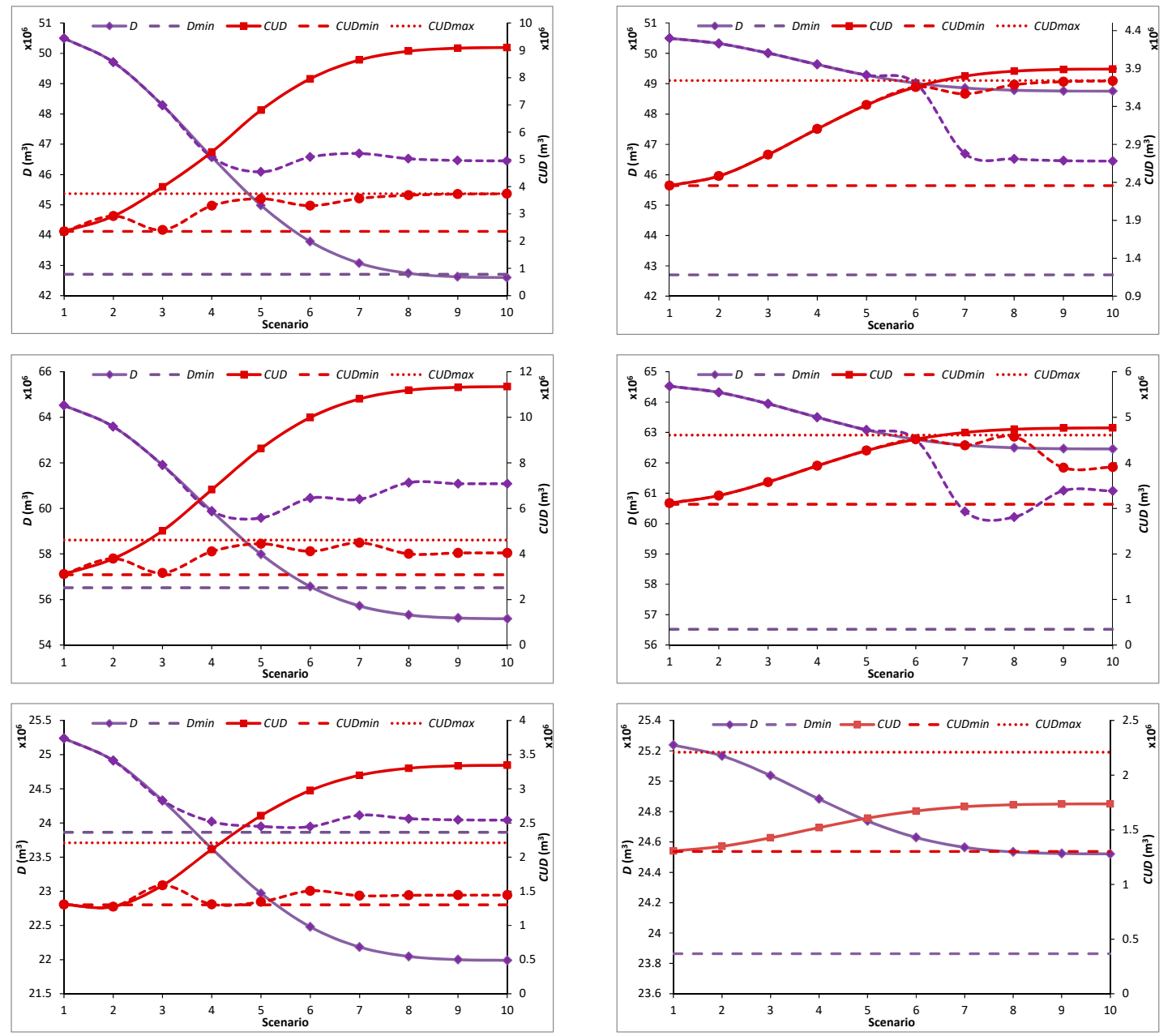

Figure 4. D and CUD results and proposed thresholds for each catchment (SZ1 first row, SZ2 s and SZ3 third), letting either intensive (left column) or semi-intensive (right column) uses to grow. 
Continuous lines displayed in Figure 4 represent $D$ and CUD for the optimal SUDs combinations (Table 3). Developing semi-intensive urban areas at the expense of rural lands does not imply failing in the proposed objectives except in SZ1 and SZ2 where CUD exceeds the upper limit for developments larger than those considered in scenarios 2 and 6, respectively. On the contrary, intensive developments more frequently break the objectives: CUD above scenario 2 and $D$ above scenario 9 in SZ1; CUD above scenario 2 and $D$ above scenario 7; SZ2 and CUD above scenario 4 and $D$ above scenario 3 in SZ3.

Dashed lines presented in Figure 4 display $D$ and CUD for the new optimal (cheapest) combination of either kgrin, kppin, and kin (intensive developments) or kgrsin, kppsin, and ksin (semi-intensive developments) required for the developments for the entire catchment to comply with the original constraints. That is, each new urban development altering the water balance to fail in meeting the objectives for $D$ and/or CUD, shall be required to provide a SUD combination such that the whole catchment complies with the original targets. Table 12 presents the new optimal (minimum cost) SUDs combination required for the new developments for the catchment to meet the original objectives.

Table 12. Optimal combination of $k_{\text {ppin }}, k_{\text {grin }}, k_{\text {in }}, k_{p p s i n}, k_{g r s i n}$, and $k_{\text {sin }}$ for new developments.

\begin{tabular}{|c|c|c|c|c|c|c|c|}
\hline Catchment & Scenario & $k_{p p i n}$ & $k_{\text {grin }}$ & $k_{\text {in }}$ & $k_{p p s i n}$ & $k_{g r s i n}$ & $k_{\sin }$ \\
\hline \multirow{8}{*}{ SZ1 } & 3 & 0 & 0 & 0.8 & & & \\
\hline & 4 & 0 & 0 & 0.9 & & & \\
\hline & 5 & 0.2 & 0 & 0.9 & & & \\
\hline & 6 & 0 & 0 & 0.9 & & & \\
\hline & 7 & 0.2 & 0.2 & 0.9 & 0.2 & 0.2 & 0 \\
\hline & 8 & 0.2 & 0.2 & 0.9 & 0.2 & 0.2 & 0 \\
\hline & 9 & 0.2 & 0.2 & 0.9 & 0.2 & 0.2 & 0 \\
\hline & 10 & 0.2 & 0.2 & 0.9 & 0.2 & 0.2 & 0 \\
\hline \multirow{8}{*}{ SZ2 } & 3 & 0 & 0 & 0.9 & & & \\
\hline & 4 & 0 & 0 & 0.9 & & & \\
\hline & 5 & 0.1 & 0.1 & 0.9 & & & \\
\hline & 6 & 0.2 & 0.2 & 0.9 & & & \\
\hline & 7 & 0.1 & 0.3 & 0.9 & 0.1 & 0.3 & 0 \\
\hline & 8 & 0.2 & 0.3 & 0.9 & 0.1 & 0.3 & 0 \\
\hline & 9 & 0.2 & 0.3 & 0.9 & 0.2 & 0.3 & 0 \\
\hline & 10 & 0.2 & 0.3 & 0.9 & 0.2 & 0.3 & 0 \\
\hline \multirow{7}{*}{ SZ3 } & 4 & 0.1 & 0.1 & 0.8 & & & \\
\hline & 5 & 0 & 0.3 & 0.8 & & & \\
\hline & 6 & 0.1 & 0.3 & 0.7 & & & \\
\hline & 7 & 0.2 & 0.3 & 0.7 & & & \\
\hline & 8 & 0.2 & 0.3 & 0.7 & & & \\
\hline & 9 & 0.2 & 0.3 & 0.7 & & & \\
\hline & 10 & 0.2 & 0.3 & 0.7 & & & \\
\hline
\end{tabular}

Urban developments are mainly required to detain and reuse runoff and, when necessary, porous pavements and green roofs are also required to preserve the limits for $D$ and $C U D$.

Figure 5 presents the expected evolution of the main water balance variables throughout the representative year using daily climatological data, $\theta_{0}=0.2$ and $V S U D_{M A X}=0$ at $t=0$. 


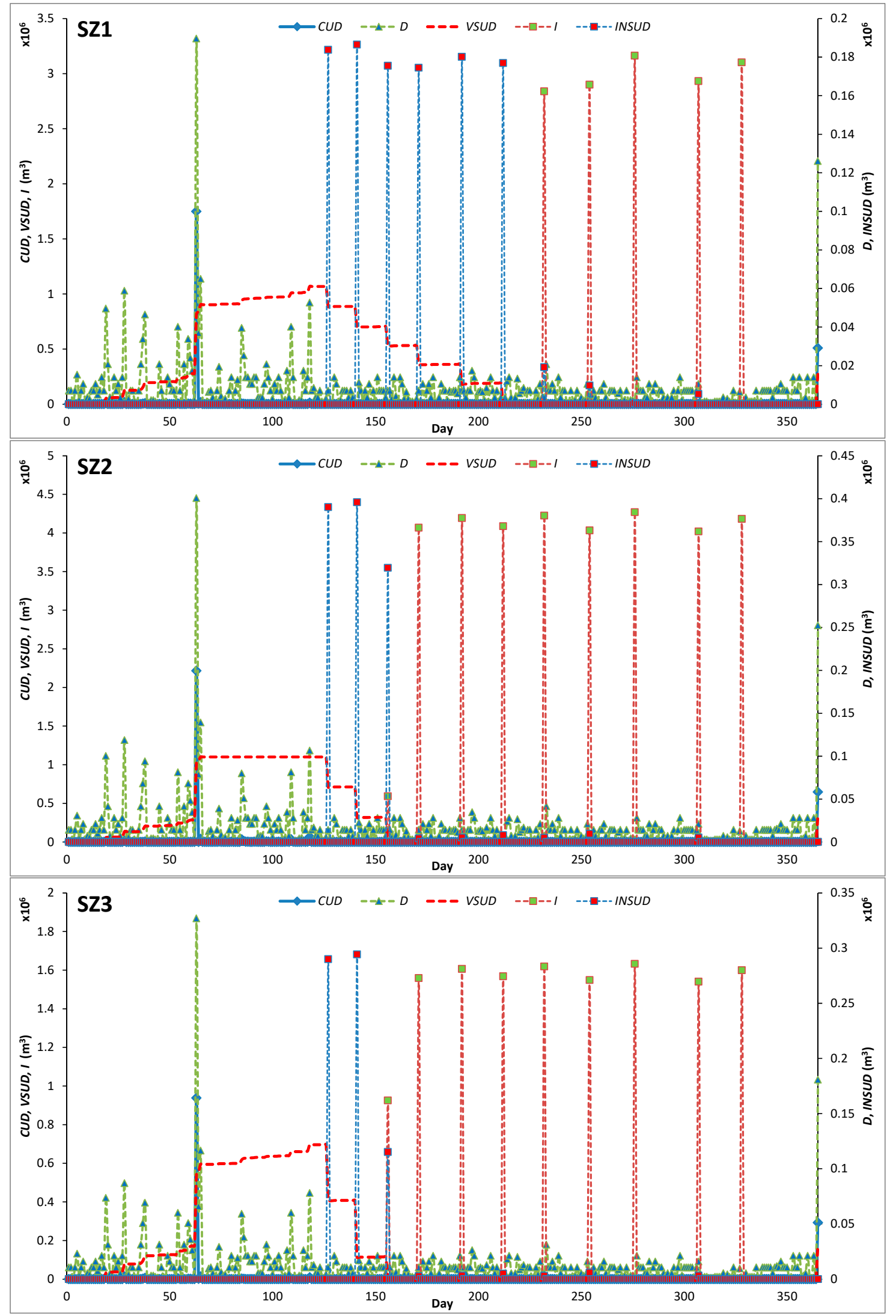

Figure 5. CUD, D, VSUD, I, and INSUD (irrigation from water stored at SUDs) evolution during the year for the three analyzed catchments (SZ1, SZ2, SZ3). 
Similar patterns were observed in the three analyzed catchments: VSUD is filling during the initial part of the year, supplying water to fulfill the irrigation requirements of three irrigation events (INSUD) at SZ2 and SZ3 and six at SZ1. VSUD ${ }_{\text {MAX }}$ almost empties after days 210 (SZ1), 150 (SZ2) and 160 (SZ3), from which irrigation is mostly provided by external sources.

Figure 6 presents the operation of the SUDs storing elements and CUD for a $1.1 \mathrm{~h}$ duration storm event of either 5 or 100 years return period and for the optimal SUDs combinations. The expected evolution of CUD in the pre-development (actual) and the runoff discharge to watercourses in the supposedly original (only rural areas) states have also been depicted in Figure 6.
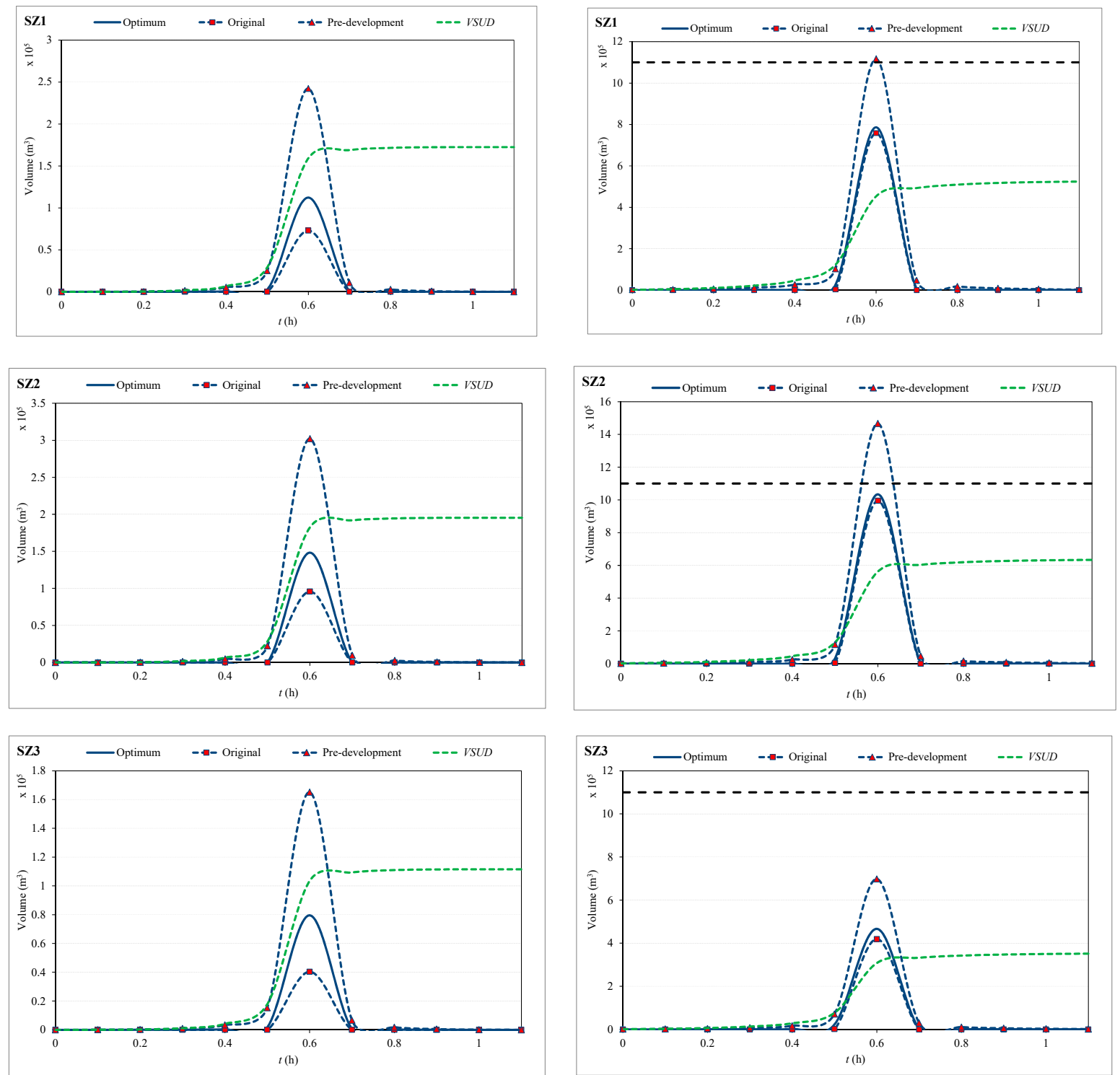

Figure 6. CUD and VSUD level for 5 (left column) and 100 (right column) years return period, $1.1 \mathrm{~h}$ duration, storm events.

The presence of SUDs helps reduce the peak flow at any catchment and return period compared to the actual (pre-development) situation. $V S U D_{M A X}$ does not fill in any case. The peak flow observed with the optimal SUDs combination is not delayed with respect to the original or pre-development cases because runoff is not completely collected and thus it is continuously discharging to CUD. Figure 7 presents the CUD increase, or reduction, for the analyzed storm events as a result of the SUDs implementation and the stored volume at VSUD during the studied events as well. 

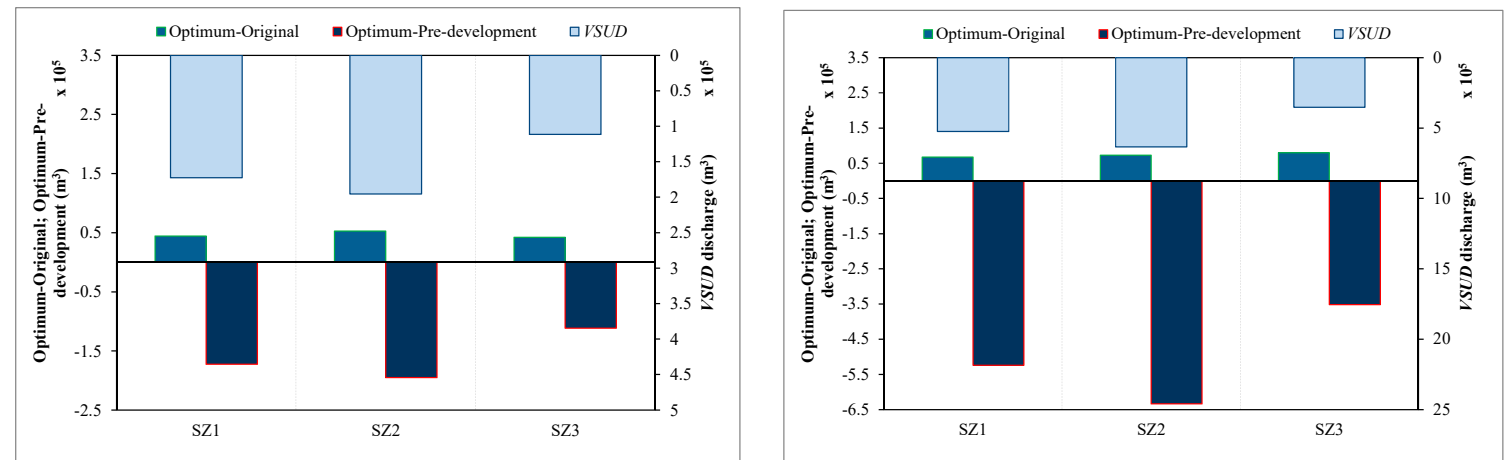

Figure 7. The difference of discharged volume to CUD between optimal SUDs combination and either the original or the predevelopment situation for a 5 (left) or 100 (right) return period storm events.

From Figure 7, it can also be observed that the proposed optimal solutions help mimic the original situation with regards to the discharged volume so the traditional requirements for SUD design (see, for example, [18]) would be met.

\section{Discussion}

We have addressed the study of the optimal SUDs combination to comply with both economic and hydrological goals. For this purpose, we have developed a Python code instead of using other models as SWMM $[23,24]$. It provided us with greater flexibility to perform specific studies such as the requirements for new developments to ensure the initial hydrological objectives are met. Although the Metropolitan Area of San Luis Potosí does not have a monitoring network for calibration and validation of the results, the estimates agree with the information of the treatment plants which could be considered an indirect validation of the model performance. Ideally, validation processes are needed to ensure the suitability of the assumptions and they must be incorporated if available.

We focused on the optimal SUDs provision from an open insight without more limitations than those related to costs, aquifer recharge, and contribution to watercourses. This approach seeks to provide the best SUDs combination aimed at mimicking the pre-development status. Other authors have focused on either finding the best SUDs combination among the enclosed set of SUD combinations $[24,25]$ or determining the optimal SUDs location [26]. In this paper, we are not delivering guidelines on where to locate SUDs facilities or proposing enclosed SUDs packages. We focus on the entire urban catchment and define the optimal solution in terms of minimum cost, required aquifer recharge, and watercourses contribution.

We considered three groups of SUDs comprising the majority of SUDs facilities aimed at either detaining and locally reusing runoff or increasing infiltration rates. Other particular SUD facilities could also be incorporated by properly defining their effect on each variable of the water balance. The method yielded the optimal SUDs combination for the catchment by comparing the results of each potential SUD combination with both the actual status and the supposedly original configuration before the urban area was developed. It allowed us to propose general criteria to be met by any other future urban development within the catchment to preserve the original targets. As a result of it, the optimal SUDs combination required for any potential urban development for ensuring that the entire catchment meets the original criteria was estimated.

The solution is sensitive to costs and the resulting optimal SUDs combinations presented in this paper are only valid for the Metropolitan Area of San Luis Potosí. The particular costs, even the set of costs, considered in this work might not be completely suitable for other regions. The issues of the cost function have to be carefully analyzed for each case-study and their temporal consistency must be ensured. The theoretical framework, based on a multi-criteria approach encompassing both economic and hydrological goals, is, however, valid for any other location. 
It can be assumed that, on average, the deduced optimal SUDs rates $\left(k_{i}, \mathrm{kgr}_{i}\right.$, and $\left.\mathrm{kpp}_{i}\right)$ generate the estimated $I, C U D$, and $D$ values as we used representative climatic data. However, the real $I, C U D$, and $D$ volumes with the optimal SUD combinations strongly depend on climatic variables. Occasionally, real values could deviate from estimates as average climatic data were used to deduce the optimal combinations. However, the aggregated results should not differ from the estimates provided that the average values were calculated using data representative of local weather conditions. In this paper, we use the average value of the median interval as we assumed that this metric better represented the nature of the data series. Any other method of providing representative values should be valid.

Other authors have also presented different multi-objective [27] or multi-criteria [13,24] routines but to the author's best knowledge none of them come up with comprehensive constraints comparable to those considered in the present paper. Most of the previous studies pose simple minimization criteria for costs or flooding, for example. On the contrary, we incorporate criteria/objectives aimed at minimizing costs and mimicking the pre-development status. It implies defining an upper limit for flooding to prevent damages, a lower limit also for flooding (or more to the point for watercourses discharge) to ensure ecological river levels and finally a minimum aquifer recharge to cover extraction rates.

The approach presented in this paper differs from those considered in various standards for example [17] that only define thresholds of peak flow and volume for particular storm events. The methodology developed in this paper does not focus on storm events but the daily evolution of the selected variables. Despite the different design approaches, the deduced optimal solutions were also checked to comply with the proposed goals for two storm events yielding satisfactory results.

\section{Conclusions}

A multi-objective decision model comprising economic and hydrological criteria is proposed to estimate the optimal SUDs combination at the urban catchment scale. Economic criteria were incorporated by a cost function encompassing costs of SUDs installation and operation. Hydrological criteria consisted of thresholds for ensuring a minimum groundwater recharge rate and both upper and lower limits for runoff to prevent flooding damages and ensure a minimum runoff contribution to watercourses. A conceptual method based on a volumetric water balance was performed to estimate the daily evolution of hydrological processes.

The method is based on urban catchments and yields the optimal SUD combination considering detention and local reuse facilities (infiltration facilities, rain gardens, or similar), green roofs, and porous pavements. The method, and the theoretical general framework, were probed for validity to find the optimal SUD combination in three urban catchments at the Metropolitan Area of San Luis Potosí (México). In this case, the optimal solutions promoted surface runoff detention and reuse over porous pavements and green roofs.

Some key points to be customized for each application have to be carefully considered, in particular: identifying representative statistics for incorporating climatic information and defining the proper set of representative costs ensuring their temporal consistency. The requirements for future urban developments for the entire catchment to keep accomplishing the original hydrological targets were estimated. It allows incorporating comprehensive SUD planning criteria for the sustainability of urban catchments to be preserved by new potential developments.

It must be remarked that the real operation of the SUD facilities could differ from the model estimates as average climatological data were used. Despite this, SUD operating conditions during particular storm events were checked and the results showed their suitability to practically mimic the pre-development status for both 5 and 100 years return period and $1.1 \mathrm{~h}$ duration storm events.

Author Contributions: Conceptualization, R.C.-A., S.Z., and A.P.-D.; methodology, S.Z.; software, S.Z.; validation, S.Z. and A.D.-P.; formal analysis, A.S.-W. and L.R.-S.; writing—original draft preparation, S.Z.; writing-review and editing, A.S.-W. and L.R.-S.; visualization, A.S.-W. and L.R.-S. All authors have read and agreed to the published version of the manuscript. 
Funding: This research received no external funding.

Conflicts of Interest: The authors declare no conflict of interest.

\section{Abbreviations}

\begin{tabular}{|c|c|}
\hline Symbol & Meaning \\
\hline SUD & Sustainable Urban Drainage System \\
\hline$S$ & Theoretical internal variation of a system \\
\hline$I P$ & Theoretical inputs of a system \\
\hline O & Theoretical outputs of a system \\
\hline$\theta$ & Soil water content (dimensionless) \\
\hline$t$ & Time $(\mathrm{T})$ \\
\hline$P$ & Precipitation $\left[\mathrm{L}^{3}\right]$ \\
\hline$I$ & Irrigation $\left[\mathrm{L}^{3}\right]$ \\
\hline ETk & Crop evapotranspiration $\left[\mathrm{L}^{3}\right]$ \\
\hline$D$ & Deep percolation $\left[\mathrm{L}^{3}\right]$ \\
\hline$R$ & Runoff $\left[\mathrm{L}^{3}\right]$ \\
\hline$k_{i}$ & Rate of runoff detention at the land use $i$ (dimensionless) \\
\hline CUD & Volume discharged to conventional urban drainage systems $\left[\mathrm{L}^{3}\right]$ \\
\hline VSUD & Volume of runoff stored at SUDs aimed at storing and reusing runoff $\left[\mathrm{L}^{3}\right]$ \\
\hline$V S U D_{M A X}$ & Maximum storing capacity of SUDs aimed at storing and reusing runoff $\left[\mathrm{L}^{3}\right.$ \\
\hline$k p p_{i}$ & Rate of porous pavement at land use $i$ (dimensionless) \\
\hline $\mathrm{kgr}_{i}$ & Rate of green roofs at land use $i$ (dimensionless) \\
\hline ETO & Potential evapotranspiration $\left[\mathrm{L}^{3}\right]$ \\
\hline$k c c$ & Crop coefficient (dimensionless) \\
\hline$C T$ & Aggregated cost $(€)$ \\
\hline $\mathrm{CU}$ & Unitary cost (either $€ / \mathrm{m}^{3}$ or $€ / \mathrm{m}^{2}$ ) \\
\hline in & Intensive residential land use \\
\hline $\sin$ & Semi-intensive residential land use \\
\hline zzvv & Green zones/sport facilities \\
\hline ag & Rural land use \\
\hline $\mathrm{CN}$ & Curve Number coefficient (dimensionless) \\
\hline SZ & Catchment/Subzone \\
\hline INSUD & Irrigation from water stored at SUDs $\left[\mathrm{L}^{3}\right]$ \\
\hline
\end{tabular}

\section{References}

1. Binesh, N.; Niksokhan, M.H.; Sarang, A.; Rauch, W. Improving sustainability of urban drainage systems for climate change adaptation using best management practices: A case study of Tehran, Iran. Hydrol. Sci. J. 2019, 64, 381-404. [CrossRef]

2. Perales-Momparler, S.; Andrés-Doménech, I.; Hernández-Crespo, C.; Vallés-Morán, F.; Martín, M.; Escuder-Bueno, I.; Andreu, J. The role of monitoring sustainable drainage systems for promoting transition towards regenerative urban built environments: A case study in the Valencian region, Spain. J. Clean. Prod. 2017, 163, S113-S124. [CrossRef]

3. Rodríguez-Sinobas, L.; Zubelzu, S.; Perales-Momparler, S.; Canogar, S. Techniques and criteria for sustainable urban stormwater management. The case study of Valdebebas (Madrid, Spain). J. Clean. Prod. 2018, 172, 402-416. [CrossRef]

4. Pappalardo, V.; La Rosa, D.; Campisano, A.; La Greca, P. The potential of green infrastructure application in urban runoff control for land use planning: A preliminary evaluation from a southern Italy case study. Ecosyst. Serv. 2017, 26, 345-354. [CrossRef]

5. Dietz, M.E. Low impact development practices: A review of current research and recommendations for future directions. Water Air Soil Pollut. 2007, 186, 351-363. [CrossRef] 
6. Fletcher, T.D.; Shuster, W.; Hunt, W.F.; Ashley, R.; Butler, D.; Arthur, S.; Trowsdale, S.; Barraud, S.; Semadeni-Davies, A.; Bertrand-Krajewski, J.L.; et al. SUDS, LID, BMPs, WSUD and more-The evolution and application of terminology surrounding urban drainage. Urban Water J. 2015, 12, 525-542. [CrossRef]

7. Elliott, A.H.; Trowsdale, S.A. A review of models for low impact urban stormwater drainage. Environ. Model. Softw. 2006, 22, 394-405. [CrossRef]

8. Li, Z.; Dong, M.; Wong, T.; Wang, J.; Kumar, A.; Singh, R. Objectives and Indexes for Implementation of Sponge Cities-A Case Study of Changzhou City, China. Water 2018, 10, 623. [CrossRef]

9. Li, H.; Ding, L.; Ren, M.; Li, C.; Wang, H. Sponge city construction in China: A survey of the challenges and opportunities. Water 2017, 9, 594. [CrossRef]

10. Meng, M.; Dabrowski, M.; Tai, Y.; Stead, D.; Chan, F. Collaborative spatial planning in the face of flood risk in delta cities: A policy framing perspective. Environ. Sci. Policy 2019, 2019 96, 95-104. [CrossRef]

11. Xu, T.; Jia, H.; Wang, Z.; Mao, X.; Xu, C. SWMM-based methodology for block-scale LID-BMPs planning based on site-scale multi-objective optimization: A case study in Tianjin. Front. Environ. Sci. Eng. 2017, 11, 1. [CrossRef]

12. Chang, N.B.; Lu, J.W.; Chui, T.F.M.; Hartshorn, N. Global policy analysis of low impact development for stormwater management in urban regions. Land Use Policy 2018, 70, 368-383. [CrossRef]

13. Wang, M.; Sweetapple, C.; Fu, G.; Farmani, R.; Butler, D. A framework to support decision making in the selection of sustainable drainage system design alternatives. J. Environ. Manag. 2017, 201, 145-152. [CrossRef]

14. Raei, E.; Alizadeh, M.R.; Nikoo, M.R.; Adamowski, J. Multi-objective decision-making for green infrastructure planning (LID-BMPs) in urban storm water management under uncertainty. J. Hydrol. 2019, 579, 124091. [CrossRef]

15. Xu, T.; Engel, B.A.; Shi, X.; Leng, L.; Jia, H.; Shaw, L.Y.; Liu, Y. Marginal-cost-based greedy strategy (MCGS): Fast and reliable optimization of low impact development (LID) layout. Sci. Total Environ. 2018, 640, 570-580. [CrossRef]

16. Giacomoni, M.H.; Joseph, J. Multi-objective evolutionary optimization and Monte Carlo simulation for placement of low impact development in the catchment scale. J. Water Resour. Plan. Manag. 2018, 143, 04017053. [CrossRef]

17. Ballard, B.W.; Wilson, S.; Udale-Clarke, H.; Illman, S.; Scott, T.; Ashley, R.; Kellaguer, R. The SuDS Manual. Construction Industry Research and Information Association; Department for Environment, Food \& Rural Affairs: London, UK, 2015.

18. Zubelzu, S.; Rodríguez-Sinobas, L.; Andrés-Domenech, I.; Castillo-Rodríguez, J.T.; Perales-Momparler, S. Design of water reuse storage facilities in Sustainable Urban Drainage Systems from a volumetric water balance perspective. Sci. Total Environ. 2019, 663, 133-143. [CrossRef]

19. Bai, Y.; Li, Y.; Zhang, R.; Zhao, N.; Zeng, X. Comprehensive Performance Evaluation System Based on Environmental and Economic Benefits for Optimal Allocation of LID Facilities. Water 2019, 11, 341. [CrossRef]

20. CONAGUA. Estadísticas del Agua en México 2018; Comisión Nacional del Agua: Ciudad de México, México, 2018.

21. CONAGUA. Actualización de la Disponibilidad Media Anual de Agua en el Acuífero San Luis Potosí (2411), Estado de San Luis Potosí; Comisión Nacional del Agua: Ciudad de México, México, 2018.

22. INTERAPAS. Informe Anual 2018; INTERAPAS: San Luis Potosí, México, 2018.

23. Mei, C.; Liu, J.; Wang, H.; Yang, Z.; Ding, X.; Shao, W. Integrated assessments of green infrastructure for flood mitigation to support robust decision-making for sponge city construction in an urbanized watershed. Sci. Total Environ. 2018, 639, 1394-1407. [CrossRef]

24. Her, Y.; Jeong, J.; Arnold, J.; Gosselink, L.; Glick, R.; Jaber, F. A new framework for modeling decentralized low impact developments using Soil and Water Assessment Tool. Environ. Model. Softw. 2018, 96, 305-322. [CrossRef]

25. Palla, A.; Gnecco, I. Hydrologic modeling of Low Impact Development systems at the urban catchment scale. J. Hydrol. 2015, 528, 361-368. [CrossRef] 
26. Martin-Mikle, C.J.; de Beurs, K.M.; Julian, J.P.; Mayer, P.M. Identifying priority sites for low impact development (LID) in a mixed-use watershed. Landsc. Urban Plan. 2015, 140, 29-41. [CrossRef]

27. Duan, H.F.; Li, F.; Yan, H. Multi-objective optimal design of detention tanks in the urban stormwater drainage system: LID implementation and analysis. Water Resour. Manag. 2016, 30, 4635-4648. [CrossRef]

(C) 2020 by the authors. Licensee MDPI, Basel, Switzerland. This article is an open access article distributed under the terms and conditions of the Creative Commons Attribution (CC BY) license (http://creativecommons.org/licenses/by/4.0/). 